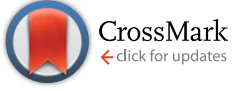

Cite this: J. Mater. Chem. A, 2015, 3, 11720

Received 9th March 2015 Accepted 28th April 2015

DOI: $10.1039 / c 5 t a 01757 b$

\section{Impact of large-scale meso- and macropore structures in adenosine-derived affordable noble carbon on efficient reversible oxygen electrocatalytic redox reactions $\dagger$}

\author{
K. Sakaushi, $\$^{*}$ S. J. Yang, T.-P. Fellinger and M. Antonietti
}

www.rsc.org/MaterialsA

In this report, we delineate a successful synthesis of a high performance and affordable adenosine-derived noble carbon cathode for LOBs with bifunctional electrocatalytic activity and show that the pore structure of the cathode is a key feature to control the electrochemical performance of this electrochemical system.

Mastering functions of energy materials is one of the most challenging topics in modern science in order to achieve a stable energy supply. ${ }^{1}$ Especially economically feasible rechargeable electrochemical energy storage is one of the most urgent requirements to realize a society equipped with an electrical grid system where renewable energies are a major component., ${ }^{2,3}$ An important enrolment of future rechargeable batteries with multiple functions is within electronic vehicles (EVs). EVs should be used to store green energy in peak times supplied from the above grid system, and it relies on material development for cost-effective but high performance electrodes, electrolytes and other components to sum up to a performance comparable to the current combustion engines. Rechargeable metal-air battery technology is expected to be able to match those expectations., ${ }^{\mathbf{4} 5}$ However, already development of Rechargeable Lithium-Oxygen Batteries (RLOBs) is hampered by their complicated electrochemical reactions. ${ }^{6-10}$ Recent results clarified the importance of electrolytes in RLOB systems, ${ }^{\mathbf{9}, 10}$ but research on the novel porous cathodes is of similar importance to improve electrochemical properties in general. ${ }^{11-16}$ The pore structure is indeed important for a RLOB system not just for oxygen supply, but for fundamental

Max Planck Institute of Colloids and Interfaces, Colloid Chemistry Department, Am Mühlenberg 1 OT Golm,D-14476 Potsdam, Germany.E-mail: sakaushi.ken@nims. go.jp

$\dagger$ Electronic supplementary information (ESI) available: Synthesis, XPS, Raman, TEM and supplementary electrochemical characterization data. See DOI: $10.1039 / \mathrm{c} 5$ ta01757b

\$ Current occupation: National Institute for Materials Science (NIMS), International Center for Materials Nanoarchitectonics (MANA), 1-1 Namiki, Tsukuba, 305-0044 Ibaraki, Japan. understanding of electrochemical reactions. ${ }^{17,18}$ Those electrochemical reactions initially occur at the interface between the catalytic cathode surface and $\mathrm{O}_{2}$-saturated electrolyte as a starting trigger, ${ }^{5,9,10}$ and then the electrochemical growth of the (insulating) lithium peroxide $\left(\mathrm{Li}_{2} \mathrm{O}_{2}\right)$ on the cathode surface drives further space-temporal development of the material structure. Here, we show that the pore structure of cathodes can obviously direct this structure formation and thereby has a significant effect on specific capacity and rechargeability of lithium-oxygen cells. We vary here the pore structures of $\mathrm{N}$-doped carbons, so-called noble carbons. In this report, we show that noble carbons synthesized from adenosine being a model for a sustainable precursor as such exhibit a high catalytic activity in both the oxygen reduction and evolution reactions, comparable to metal-based catalysts.

The promising properties in catalytic reactions of doped carbons are not new as such. ${ }^{\mathbf{1 9 - 2 6}}$ In our previous report we described mesoporous Noble Carbons (NCs), constituted mainly of the elements $\mathrm{C}$ and $\mathrm{N}$ and therefore being sustainable and affordable, to be an efficient bifunctional catalyst working for both the oxygen reduction reaction (ORR) and oxygen evolution reaction (OER) in non-aqueous RLOB systems. ${ }^{27}$ The RLOB cell using an ionic liquid (IL) based porous NC cathode exhibited a comparably low overpotential during charge and discharge cycles. In the OER, the mesoporous NC cathode already showed an overpotential of "only" $0.45 \mathrm{~V}$, a performance comparable to cathodes using expensive noble metal catalysts such as $\mathrm{Au} .{ }^{28}$ Although there is a problem on the reactivity during both charge and discharge reactions, ${ }^{29-31}$ recent research using differential electrochemical mass-spectrometers confirmed that carbon-based cathodes are one of the most promising catalysts for reversible chargedischarge reactions of RLOBs. ${ }^{8}$ Therefore, we intend here to perform further investigation on large-scale meso/macroscopic pore structures to improve rechargeability and cycling life by controlling the porous structure of the noble carbon cathode. This was performed by applying salt melt synthesis, which can enable the synthesis of materials with controlled 

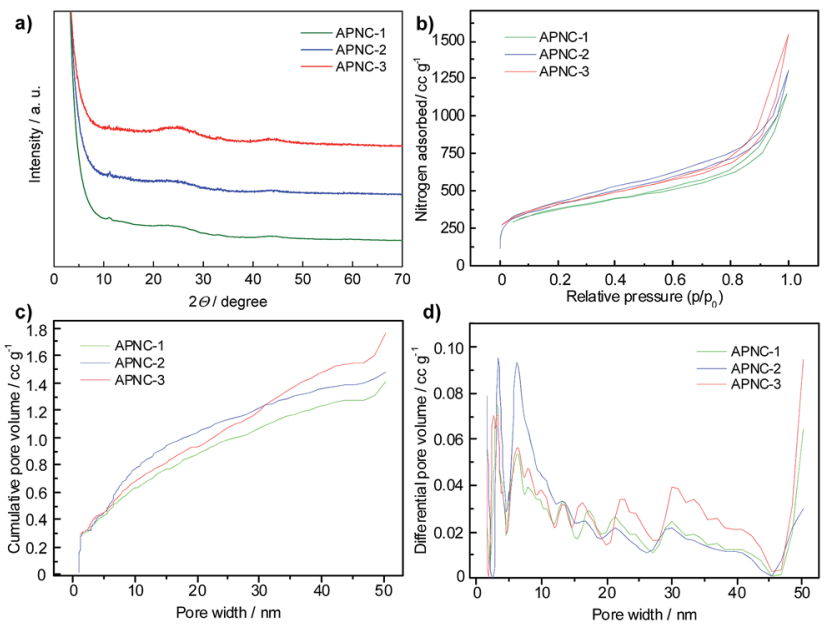

Fig. 1 Physical characterization of APNCs. (a) XRD patterns. (b) $\mathrm{N}_{2}$ isotherms. (c) Pore width vs. cumulative pore volume diagrams. (d) Pore size distributions.

pore structures. ${ }^{32}$ Adenosine was selected as a clean model for DNA-derived sustainable precursors towards materials with electrocatalytic properties as good as IL-based noble carbons. The resulting adenosine-based porous noble carbons (APNCs) have a different large-scale meso- and macroporosity without any change of microporosity and chemical structure. The pore structure of NCs has indeed a significant effect on the specific capacity and rechargeability of RLOB cells: the APNC showing the best performance within our sample set has a high amount of large-scale meso- and macroporosity. With larger pore volume contributed by macropores the RLOB cell shows a lower overpotential and a high specific capacity, while the APNC having fewer macropores only showed low specific capacity.

The APNCs were synthesized by adding adenosine to a binary salt mix (a combination of $\mathrm{KCl}$ and $\mathrm{ZnCl}_{2}$ with a mass ratio of 1.00 to 1.75$)$. The "salt-melt synthesis" as a template procedure enables us to control the pore volume in carbonaceous materials with high specific surface area by just changing the ratio of starting material and a salt. ${ }^{32}$ The technique was applied to have a series of $\mathrm{N}$-doped carbons with the same micropore volume, but different controlled meso- and macropore structures. Adenosine was chosen as the carbon source because it provides a high carbonization yield with high nitrogen content and a favourable oxidation stability of the final material. Adenosine as such is rather expensive but is to be understood as a model for digested bacterial DNA, a comparably cheap, sustainable product of fermentation which allows the scalability of the process. We chose three ratios of adenosine and salts (A : S) as A $: S=5: 1$ (described as APNC-1), A : S = 5:2.5 (APNC-2), and $\mathrm{A}: \mathrm{S}=5: 5$ (APNC-3). Then, the samples were carbonized at $1000{ }^{\circ} \mathrm{C}$ for two hours and washed with distilled water overnight, resulting in the production of three different APNCs. Although the X-ray diffraction (XRD) patterns of APNCs show weak diffraction intensity which, in our experience, suggests nanometer carbon wall thickness and high porosity, the broadened (002) peak indicated the graphitized character of the resultant carbon materials (Fig. 1a). The results of elemental analysis (EA) showed that the N-content of all APNCs is around $5 \%$ (Table S1 $\dagger$ ). The chemical structures of doped nitrogen in all three samples were confirmed using an X-ray photoemission spectrometer (XPS). The results of XPS showed that the chemical structures of nitrogen in three samples are almost the same (Fig. S1†). Indeed, Raman spectroscopy also revealed that the physico-chemical nature of all three samples is similar (Fig. S2 $\dagger$ ). The surface textural characteristics of the APNCs were quantified by measuring the $\mathrm{N}_{2}$ isotherms at a cryogenic condition (77 K) (Fig. 1b-d and Table 1). Overall, the $\mathrm{N}_{2}$ isotherms of the APNCs exhibited combined characteristics of typical type I and IV materials. A steep increase in low pressure was observed, followed by a moderate slope at intermediate pressure accompanied by a small desorption hysteresis and a dramatic increase at a relative pressure of nearly 1.0. These properties indicated the combined presence of micro-, meso-, and macrosized pores. From Table 1 and pore size distribution (Fig. 1c and d), extracted from the isotherms using non-local density functional theory (NLDFT), clear differences in the pore structure of the samples can be found..$^{33}$ As the amount of salt template increased, large-scale meso- and macroporosity of the resulting carbons could form without notable changes of the microporosity and the specific surface area (Fig. 1b and c). Scanning electron microscopy (SEM) and transmission electron microscopy (TEM) observations revealed that APNC-1 exhibits an apparently smooth surface, i.e. macropores are absent, while APNC-3 shows a morphology of interconnected carbon nanoparticles with interstitial large-scale meso- and macropores (Fig. 2 and $\mathrm{S} 3 \dagger$ ). The large-scale mesoporosity and macroporosity of APNC-3 (Fig. 1d, 2c and S3†) not only provide transport channels for improved contact with oxygen, but also enable rapid long range transport of electrolyte ions.

Together with XRD, SEM, TEM, EA, XPS, and Raman results, these observations demonstrate that the pore characteristics of the resulting carbons are easily tuned by controlling the amount of salt used while maintaining the physical-chemical wall

Table $1 \mathrm{~N}_{2}$ sorption data for APNCs

\begin{tabular}{|c|c|c|c|c|}
\hline Sample & $\begin{array}{l}\text { BET surface } \\
\text { area }\left(\mathrm{m}^{2} \mathrm{~g}^{-1}\right)\end{array}$ & $\begin{array}{l}\text { Micropore volume } \\
\left(\mathrm{cm}^{3} \mathrm{~g}^{-1}\right)\end{array}$ & $\begin{array}{l}\text { Mesopore volume } \\
\left(\mathrm{cm}^{3} \mathrm{~g}^{-1}\right)\end{array}$ & $\begin{array}{l}\text { Total pore volume } \\
\left(\mathrm{cm}^{3} \mathrm{~g}^{-1}\right)\end{array}$ \\
\hline APNC-1 & 1321 & 0.308 & 1.106 & 1.778 \\
\hline APNC-3 & 1476 & 0.320 & 1.440 & 2.387 \\
\hline
\end{tabular}




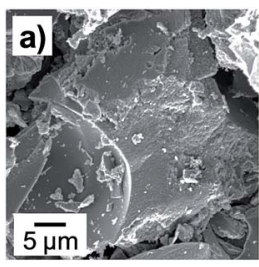

d)

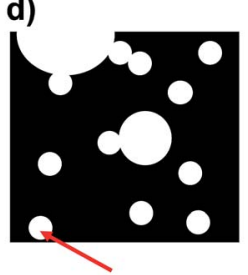

Micropore

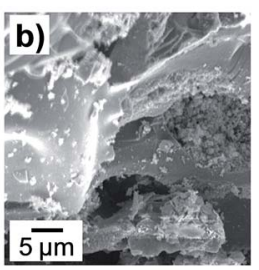

e)

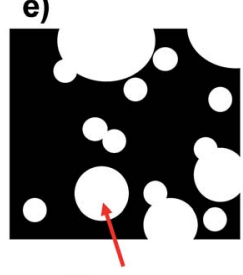

Mesopore
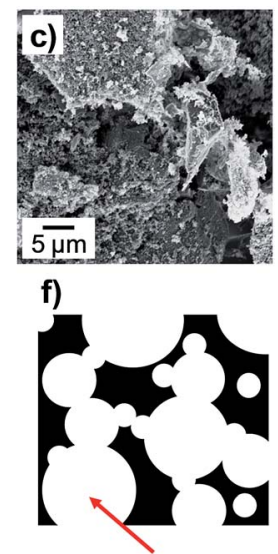

Macropore
Fig. 2 SEM images ( $a$ and $b$ ) and schematic illustrations ( $d$ and e) of APNCs.

Table 2 Electrochemical properties of APNCs

\begin{tabular}{llllll}
\hline Cathode & $\begin{array}{l}Q_{\text {dis }} \\
\left.(\mathrm{mA} \mathrm{h} \mathrm{g})^{-1}\right)\end{array}$ & $\begin{array}{l}Q_{\text {rec }} \\
\left(\mathrm{mA} \mathrm{h} \mathrm{g}^{-1}\right)\end{array}$ & $Q_{\text {rec }} / Q_{\text {dis }}$ & $\eta_{\text {dis }}(\mathrm{V})$ & $\eta_{\text {rec }}(\mathrm{V})$ \\
\hline APNC-1 & 912 & 579 & 0.64 & 0.39 & 0.61 \\
APNC-2 & 1394 & 921 & 0.66 & 0.37 & 0.49 \\
APNC-3 & 1767 & 1380 & 0.78 & 0.29 & 0.45
\end{tabular}

structure. The following electrochemical properties are thereby mainly affected by the pore structure of the samples.

The charge-discharge curves of APNCs in a LOB set-up indicate that there is a strong impact of porosity on the electrochemical performance. We applied $2.3 \mathrm{~V} v s$. $\mathrm{Li} / \mathrm{Li}^{+}$as the lower cut-off voltage and $4.0 \mathrm{~V} v$ s. $\mathrm{Li}^{-\mathrm{Li}^{+}}$as the upper cut-off voltage. The upper cut-off voltage was chosen to minimize the irreversible specific capacity which caused by side reactions
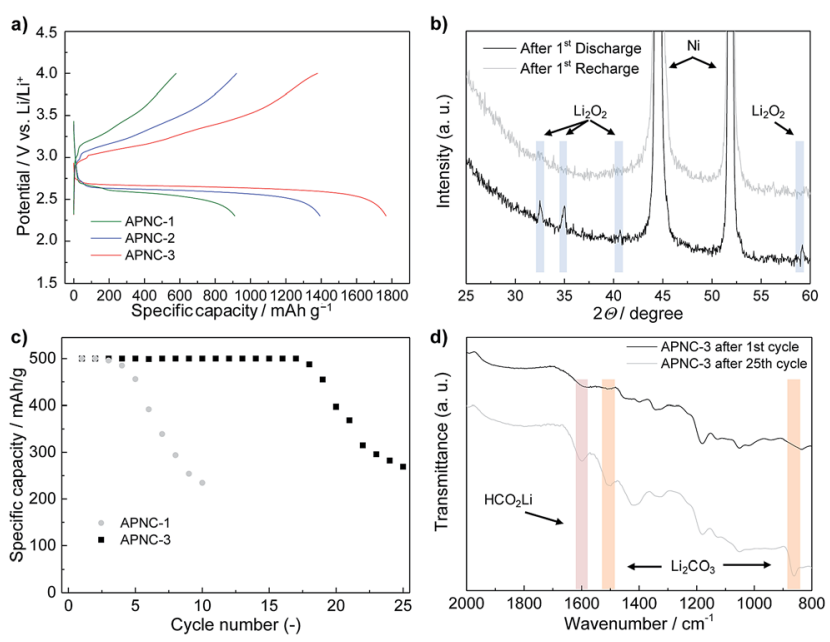

Fig. 3 (a) Charge-discharge curves of APNCs. (b) Ex situ XRD pattern of APNC-3 after the $1^{\text {st }}$ discharge and recharge. (c) Cycle performance of APNC-1 and APNC-3. (d) Ex situ FTIR spectra of APNC-3 after the $1^{\text {st }}$ cycle and the $25^{\text {th }}$ cycle. from the electrolyte decomposition as previous research clearly showed the $\mathrm{CO}_{2}$ evolution above $4.0 \mathrm{~V} v s$. $\mathrm{Li} / \mathrm{Li}^{+}$by quantitative differential electrochemical mass spectroscopy. ${ }^{29,34,35} \mathrm{~A}$ current density of $100 \mathrm{~mA} \mathrm{~g}^{-1}$ was selected for this experiment. Our electrochemical data of APNCs are summarized in Table 2. The charge-discharge curves of APNCs show that already the bare Ndoped carbon materials without any metal exhibit bifunctional catalytic properties for both the oxygen reduction reaction and oxygen evolution reaction at discharge and charge states, respectively (Fig. 3a). Formation of $\mathrm{Li}_{2} \mathrm{O}_{2}$ is confirmed by XRD after the $1^{\text {st }}$ discharge (Fig. $3 \mathrm{~b}$ ). The APNC-3 cathode having a high macropore volume shows a specific discharge capacity of $\sim 1800 \mathrm{~mA} \mathrm{~h} \mathrm{~g}{ }^{-1}$ already without optimization of secondary parameters. APNC-1, having the lowest macropore volume, shows under the same conditions a specific discharge capacity of $\sim 900 \mathrm{~mA} \mathrm{~h} \mathrm{~g}^{-1}$ (Fig. 3a). If we analyze in more detail the discharge process, the APNC-3 cathode starts the formation of $\mathrm{Li}_{2} \mathrm{O}_{2}\left(=\mathrm{O}_{2}+2 \mathrm{Li}^{+}+2 \mathrm{e}^{-} \rightarrow \mathrm{Li}_{2} \mathrm{O}_{2}\right)$ from $2.67 \mathrm{~V}$ vs. $\mathrm{Li} / \mathrm{Li}^{+}$and exhibits an average discharge overpotential $\left(\eta_{\text {dis }}\right)$ of $0.29 \mathrm{~V}$, while the APNC-1 cathode can drive the $\mathrm{Li}_{2} \mathrm{O}_{2}$ formation starting from $2.60 \mathrm{~V} v s$. $\mathrm{Li} / \mathrm{Li}^{+}$and shows an $\eta_{\text {dis }}$ of $0.39 \mathrm{~V} v$ s. $\mathrm{Li} / \mathrm{Li}^{+}$(Table 2 and ESI Fig. S4 $\uparrow)$. For the recharge reaction $\left(=\mathrm{Li}_{2} \mathrm{O}_{2} \rightarrow \mathrm{O}_{2}+\right.$ $2 \mathrm{Li}^{+}+2 \mathrm{e}^{-}$), the APNC-3 cathode can start the reaction at $3.0 \mathrm{~V} v s$. $\mathrm{Li} / \mathrm{Li}^{+}$and show an average recharging overpotential ( $\left.\eta_{\text {cha }}\right)$ of $0.45 \mathrm{~V}$, while the APNC-1 cathode starts the recharge reaction from $3.17 \mathrm{~V} v s$. $\mathrm{Li} / \mathrm{Li}^{+}$with an overpotential of $0.61 \mathrm{~V}$ (Table 2 and ESI Fig. S5†).

The value given by $Q_{\mathrm{rec}} / Q_{\mathrm{dis}}$ at the $1^{\text {st }}$ cycle characterizes the general loss for the conditioning/formation of the solid electrolyte interface and is another measure for the quality and inertness of the electrode (note that the later Coulombic efficiency is much higher, as expected for a real battery system). The APNC-3 cathode shows a $Q_{\text {rec }} / Q_{\text {dis }}$ of 0.78 while the APNC-1 cathode shows 0.64 , which means that the APNC-3 cathode relies on less reaction with the Li system to become electrochemically stable (Table 2). These results experimentally confirm that a theoretical study showing pore structure takes a very important enrolment during electrochemical redox reactions related to oxygen at the cathode. ${ }^{5}$ Charge-discharge cycling while limiting the specific loading capacity to $500 \mathrm{~mA} \mathrm{~h} \mathrm{~g}^{-1}$ while applying a harsher current density of $250 \mathrm{~mA} \mathrm{~g}^{-1}$ was carried out to check the relationship between the pore structure and cycling performance by using APNC-1 and APNC-3 (Fig. 3c). From the results, we found that the APNC-3 cathode has a longer cycling stability compared to the APNC-1 cathode. It is noted that these results on the rechargeability and cycling performance are still affected by the side reactions and degradation of the Li metal anode caused by exposure to oxygen, ${ }^{36}$ i.e. the degradation is not only due to the cathode, but also due to the suboptimal anode design and solvent/salt effects. Future engineering work on the cell configuration is certainly necessary to lever the real potential of noble carbon cathodes. Previous theoretical research in this battery system suggested that the pore structure of a cathode has a stronger effect on the electrochemical performance in this system: pore blocking may be a reason for rate as well as capacity limitation since insulating $\mathrm{Li}_{2} \mathrm{O}_{2}$ or side products form on the surface of porous carbon and 
Table 3 Comparison of rechargeability for various carbon-based cathodes

\begin{tabular}{|c|c|c|c|c|c|c|c|c|}
\hline Cathode & $Q_{\text {rec }} / Q_{\text {dis }}$ & $\begin{array}{l}Q_{\text {dis }} \\
\left(\mathrm{mA} \mathrm{h} \mathrm{g}^{-1}\right)\end{array}$ & $\begin{array}{l}Q_{\text {rec }} \text { up to } 4.0 \mathrm{~V} v s . \mathrm{Li} / \mathrm{Li}^{+} \\
\left(\mathrm{mA} \mathrm{h} \mathrm{g}^{-1}\right)\end{array}$ & $\begin{array}{l}\text { Current density/ } \\
\left(\mathrm{mA} \mathrm{g}^{-1}\right)\end{array}$ & Electrolyte & Anode & $S_{\text {BET }}\left(\mathrm{m}^{2} \mathrm{~g}^{-1}\right)$ & Ref. \\
\hline APNC-3 & 0.78 & 1767 & 1380 & 100 & $1 \mathrm{M}$ LiTFSI in TEGDME & Li metal & 1476 & $\begin{array}{l}\text { This } \\
\text { work }\end{array}$ \\
\hline XC-72 & 0.67 & 300 & $\sim 200$ & 400 & $1 \mathrm{M}$ LiTFSI in DME & Li metal & Typically $\sim 250$ & 35 \\
\hline Carbon & 0.62 & 900 & 566 & 70 & $0.5 \mathrm{M} \mathrm{LiPF}_{6}$ in TEGDME & $\mathrm{LiFePO}_{4}$ & 150 & 34 \\
\hline GNSs & 0.47 & 2359 & $\sim 1100$ & 50 & $1 \mathrm{M} \mathrm{LiCIO}_{4}$ in $\mathrm{PC}$ & Li metal & 309 & 29 \\
\hline
\end{tabular}

cap the pores. ${ }^{5}$ This results in passivating the carbon and/or blocking the oxygen supply to the catalytic carbon surface. Actually, the electronic conductivity could decrease dramatically even after monolayer deposition of $\mathrm{Li}_{2} \mathrm{O}_{2} \cdot{ }^{37}$ In addition, there is a deposition of side products, such as $\mathrm{Li}_{2} \mathrm{CO}_{3}$, during charge-discharge reactions. ${ }^{34}$ We could confirm the formation of $\mathrm{Li}_{2} \mathrm{CO}_{3}$ and side products after the $25^{\text {th }}$ cycle (Fig. $3 \mathrm{~d}$ ).

A comparison of the rechargeability of APNC-3 with previous research results using carbon-based cathodes is shown in Table $3 .^{29,35,38-40}$ The specific capacity obtained above $4.0 \mathrm{~V} v s . \mathrm{Li}^{-} \mathrm{Li}^{+}$ contains the irreversible capacity from the electrolyte decomposition..$^{29,34,35}$ Therefore, we only compared the specific capacity in these data up to $4.0 \mathrm{~V} v s$. $\mathrm{Li}^{-} \mathrm{Li}^{+}$to assess a more comparable electrochemical performance of the cathodes at the recharging reaction $\left(=\mathrm{OER} ; \mathrm{Li}_{2} \mathrm{O}_{2} \rightarrow \mathrm{O}_{2}+2 \mathrm{Li}^{+}+2 \mathrm{e}^{-}\right)$. From this comparison, it is shown that APCN-3 is to date one of the best performing carbon-based cathodes used in RLOBs. For example, a carbon-nanotube-based cathode showed no performance as it cannot start the recharging reaction below $4.0 \mathrm{~V} v$ s. $\mathrm{Li} / \mathrm{Li}^{+}$since the lack of electrocatalytic performance.

\section{Conclusions}

In conclusion, we delineated a successful synthesis of a high performance and affordable adenosine-derived noble carbon cathode for LOBs with bifunctional electrocatalytic activity and showed that the pore structure of APNCs is a key feature to control the electrochemical performance of this electrochemical system. The pore structure of APNCs is tuned by the amount of salt, thereby producing highly $\mathrm{N}$-doped porous carbons with different meso- and macropore volumes. Such a pore structure successfully minimizes the influence of the discharge product $\mathrm{Li}_{2} \mathrm{O}_{2}$ or side products on the electrode performance. We demonstrated a favourable electrochemical performance of the optimized cathode with less side reaction by operating the cell below $4.0 \mathrm{~V} v s . \mathrm{Li}^{\prime} \mathrm{Li}^{+}$at the recharging reaction. From these results and our previous report, ${ }^{27}$ a noble nitrogen-doped porous carbon possessing a high surface area together with large-scale accessible porosity would be the best carbon-based cathode for $\mathrm{Li}-\mathrm{O}_{2}$ battery systems. Although porous Au outperforms APNC cathodes, we believe that a sustainable and affordable character is necessary within the development of real life, scalable battery systems.

\section{Acknowledgements}

K.S. is indebted to Max Planck Society. We thank Mr Jaeho Kim (Seoul National University) for the XPS and Raman spectroscopy measurements. The technical staff members are acknowledged for standard analysis.

\section{Notes and references}

1 M. S. Dresselhaus and I. L. Thomas, Nature, 2001, 414, 332337.

2 B. Dunn, H. Kamath and J.-M. Tarascon, Science, 2011, 334, 928-935.

3 IEA, World Energy Outlook 2014, IEA, 2014.

4 G. Girishkumar, B. McCloskey, A. C. Luntz, S. Swanson and W. Wilcke, J. Phys. Chem. Lett., 2010, 1, 2193.

5 J. Christensen, P. Albertus, R. S. Sanchez-Carrera, T. Lohmann, B. Kozinsky, R. Liedtke, J. Ahmed and A. Kojic, J. Electrochem. Soc., 2012, 159, R1.

6 Y.-C. Lu, B. M. Gallant, D. G. Kwabi, J. R. Harding, R. R. Mitchell, M. S. Whittingham and Y. Shao-Horn, Energy Environ. Sci., 2013, 6, 750.

7 C. O. Laoire, S. Mukerjee, K. M. Abraham, E. J. Plichta and M. A. Hendrickson, J. Phys. Chem. C, 2010, 114, 9178.

8 B. D. McCloskey, R. Scheffler, A. Speidel, D. S. Bethune, R. M. Shelby and A. C. Luntz, J. Am. Chem. Soc., 2011, 133, 18038.

9 L. Johnson, C. Li, Z. Liu, Y. Chen, S. A. Freunberger, P. C. Ashok, B. B. Praveen, K. Dholakia, J.-M. Tarascon and P. G. Bruce, Nat. Chem., 2014, 6, 1091.

10 N. B. Aetukuri, B. D. McCloskey, J. M. Garcia, L. E. Krupp, V. Viswanathan and A. C. Luntz, Nat. Chem., 2015, 7, 50.

11 L. Zhao, L.-Z. Fan, M.-Q. Zhou, H. Guan, S. Qiao, M. Antonietti and M.-M. Titirici, Adv. Mater., 2010, 22, 5202. 12 K. Sakaushi, G. Nickerl, F. M. Wisser, D. Nishio-Hamane, E. Hosono, H. Zhou, S. Kaskel and J. Eckert, Angew. Chem., Int. Ed., 2012, 51, 7850.

13 N. Brun, K. Sakaushi, L. Yu, L. Giebeler, J. Eckert and M. M. Titirici, Phys. Chem. Chem. Phys., 2013, 15, 6080.

14 K. Sakaushi, E. Hosono, G. Nickerl, T. Gemming, H. Zhou, S. Kaskel and J. Eckert, Nat. Commun., 2013, 4, 1485.

15 J. Liu, T. Yang, D.-W. Wang, G. Q. Lu, D. Zhao and S. Z. Qiao, Nat. Commun., 2013, 4, 2798. 
16 H.-W. Liang, Z.-Y. Wu, L.-F. Chen, C. Li and S.-H. Yu, Nano Energy, 2015, 11, 366.

17 G. Ertl, Angew. Chem., Int. Ed., 2008, 47, 3524.

18 J. Sauer and H.-J. Freund, Catal. Lett., 2015, 145, 109.

19 J. P. Paraknowitsch and A. Thomas, Energy Environ. Sci., 2013, 6, 2839.

20 K. Sakaushi and M. Antonietti, Bull. Chem. Soc. Jpn., 2015, 88, 386.

21 M. Glerup, M. Castignolles, M. Holzinger, G. Hug, A. Loiseau and P. Bernier, Chem. Commun., 2003, 2542.

22 F. Jaouen, M. Lefèvre, J.-P. Dodelet and M. Cai, J. Phys. Chem. $B, 2006,110,5553$.

23 R. Liu, D. Wu, X. Feng and K. Müllen, Angew. Chem., Int. Ed., 2010, 49, 2565.

24 J. P. Paraknowitsch, J. Zhang, D. Su, A. Thomas and M. Antonietti, Adv. Mater., 2010, 22, 87.

25 W. Yang, T.-P. Fellinger and M. Antonietti, J. Am. Chem. Soc., 2011, 133, 206.

26 N. Ranjbar Sahraie, J. P. Paraknowitsch, C. Göbel, A. Thomas and P. Strasser, J. Am. Chem. Soc., 2014, 136, 14486.

27 K. Sakaushi, T.-P. Fellinger and M. Antonietti, ChemSusChem, 2015, 8, 1156.

28 Z. Peng, S. A. Freunberger, Y. Chen and P. G. Bruce, Science, 2012, 337, 563.

29 M. M. Ottakam Thotiyl, S. A. Freunberger, Z. Peng and P. G. Bruce, J. Am. Chem. Soc., 2013, 135, 494.

30 J. Lu, Y. Lei, K. C. Lau, X. Luo, P. Du, J. Wen, R. S. Assary, U. Das, D. J. Miller, J. W. Elam, H. M. Albishri, D. A. El-
Hady, Y.-K. Sun, L. A. Curtiss and K. Amine, Nat. Commun., 2013, 4, 2383.

31 D. M. Itkis, D. A. Semenenko, E. Y. Kataev, A. I. Belova, V. S. Neudachina, A. P. Sirotina, M. Hävecker, D. Teschner, A. Knop-Gericke, P. Dudin, A. Barinov, E. A. Goodilin, Y. Shao-Horn and L. V. Yashina, Nano Lett., 2013, 13, 4697.

32 N. Fechler, T.-P. Fellinger and M. Antonietti, Adv. Mater., 2013, 25, 75.

33 Y. Ren, Z. Ma, R. E. Morris, Z. Liu, F. Jiao, S. Dai and P. G. Bruce, Nat. Commun., 2013, 4, 2015.

34 B. D. McCloskey, D. S. Bethune, R. M. Shelby, G. Girishkumar and A. C. Luntz, J. Phys. Chem. Lett., 2011, 2, 1161.

35 B. D. McCloskey, D. S. Bethune, R. M. Shelby, T. Mori, R. Scheffler, A. Speidel, M. Sherwood and A. C. Luntz, J. Phys. Chem. Lett., 2012, 3, 3043.

36 J. Hassoun, H.-G. Jung, D.-J. Lee, J.-B. Park, K. Amine, Y.-K. Sun and B. Scrosati, Nano Lett., 2012, 12, 5775.

37 B. D. McCloskey, A. Speidel, R. Scheffler, D. C. Miller, V. Viswanathan, J. S. Hummelshøj, J. K. Nørskov and A. C. Luntz, J. Phys. Chem. Lett., 2012, 3, 997.

38 Y. Li, J. Wang, X. Li, J. Liu, D. Geng, J. Yang, R. Li and X. Sun, Electrochem. Commun., 2011, 13, 668.

39 B. Sun, B. Wang, D. Su, L. Xiao, H. Ahn and G. Wang, Carbon, 2012, 50, 727.

40 J. Shui, F. Du, C. Xue, Q. Li and L. Dai, ACS Nano, 2014, 8, 3015. 